\title{
O silício em águas subterrâneas do Brasil
}

\author{
The silicon in Brazilian groundwater
}

\author{
Fábio Tadeu Lazzerini ${ }^{1}$, Daniel Marcos Bonotto ${ }^{2}$ \\ 1,2 Universidade Estadual Paulista “Julio Mesquita Filho", Rio Claro, SP, Brasil
}

\begin{abstract}
Resumo
Elemento presente em processos ocorrendo desde a formação da Terra, o silício é o sólido mais abundante e disperso no ambiente crustal. Sua ocorrência na geosfera, mesmo em baixas concentrações, é fundamental nos processos geológicos, hidrológicos e biológicos. As águas minerais costumam conter o silício em sua forma biodisponível, de comprovados benefícios para a saúde humana. Não estando prevista a classificação de águas silicatadas na legislação brasileira e sendo poucos os estudos hidroquímicos enfocando suas potenciais aplicações à saúde humana, espera-se com este trabalho contribuir com este conhecimento. Para tanto, foi realizada uma extensa revisão bibliográfica, de exemplos internacionais, sobre sua utilização medicinal, hidroterapêutica e nutricional, bem como dos teores adequados para silício nas águas. O inventário hidroquímico e geográfico elaborado permitiu avaliar e comparar 322 ocorrências do silício, em águas subterrâneas do país, entre si e com exemplos de outros países. A intersecção entre os dois conjuntos de informações permitiu inferir que águas silicatadas são benéficas aos tecidos e estruturas ósseas dos seres vivos, bem como no combate da toxicidade devido ao Al. Os teores encontrados são anormalmente elevados e correlações hidroquímicas e hidrogeológicas, equivalentes à bibliografia consultada, indicam grande potencial de aproveitamento destes recursos hídricos no Brasil.
\end{abstract}

Palavras-chave: silício. águas silicatadas. balneários. hidrogeologia. bioatividade.

\begin{abstract}
Element present in processes since the Earth formation, silicon is the most abundant and dispersed solid in the crustal environment. Its occurrence in geosphere, even in low concentrations, is fundamental in geological, hydrological and biological processes. The mineral waters often contain silicon in its bioavailable form of proven benefits for human health. The Brazilian legislation does not classify siliceous waters and little hydrochemical studies focus their potential application to human health, thus, this paper aims to increase this knowledge. For this purpose, it was performed a large bibliographic review of international examples about their use in medicine, hydrotherapy and nutrition, as well on the appropriate silicon contents in waters. The hydrochemical and geographical inventory allowed evaluate and compare 322 occurrences of silicon in groundwater in the country, with each other and with examples from other countries. The intersection between the two sets of information permitted to infer that the siliceous waters are benefit to tissues and osseous structures of living beings, as well as in Al toxicity prevention. The anomalously high Si levels reported in the database and the hydrochemical and hydrogeological correlations equivalent to the bibliography consulted have indicated great potential of utilization of these hydric resources in Brazil.
\end{abstract}

Keywords: silicon. siliceous waters. SPAs. hydrogeology. bioactivity. 


\section{Introdução}

A sílica $\left(\mathrm{SiO}_{2}\right)$ é a substância mais abundante do planeta Terra, constituindo $59,12 \%$ da crosta (que representa $0,4 \%$ da massa global), $45 \%$ do manto (representando $67 \%$ da massa global), sendo também encontrada em menores proporções no núcleo ( $32,4 \%$ da massa global).

Como minerais, os silicatos possuem predomínio ainda mais evidente na crosta terrestre, com a maior diversidade cristalográfica do reino mineral (mais de 500 espécies). Os aluminossilicatos, compostos dos três elementos químicos mais abundantes (oxigênio, silício e alumínio), representam $75 \%$ da massa litosférica total e seus mais comuns minerais primários (endógenos) são os feldspatos e secundários (exógenos ou de alteração) as argilas. O grupo da sílica pura, principalmente sob a forma de quartzo, distribui-se em $12 \%$ da massa global dos silicatos.

O silício fundamenta estruturas e processos geológicos, biológicos, antropológicos e econômicos, sendo um dos principais componentes de toda matéria viva desde sua origem. Nas condições ambientais atmosféricas e subterrâneas, sua resistência e solidez caracterizam suas ocorrências. Na tabela periódica, o silício possui uma das maiores condutividades térmicas, ponto de fusão e de vaporização e tamanho das unidades cristalinas, exibindo baixa condutividade elétrica. Na escala logarítmica de Mohs (1 a 10), a sílica tem dureza 7, ou seja, é a quarta substância mais dura na natureza. E dentro de sua diversidade, outro silicato, o talco, é o mais mole ao risco físico, com dureza 1 desta escala.

Uma propriedade natural peculiar e interessante do silício ocorre nos minerais de quartzo e turmalina: o efeito piezoelétrico. Consiste na capacidade de gerar campo elétrico em sua superfície, quando esta é submetida à pressão, especialmente se coincidente aos extremos de seus eixos cristalográficos. Na mesma intensidade, mas de maneira inversa, ao se aplicar voltagem, o volume deste mineral sofre pequenas mudanças.

Os minerais de silicato são insumos para quase todos os setores econômicos e tipos de indústria: química, metalúrgica, automobilística, bélica, agregados de construção civil, cerâmica, farmacosmética, alimentícia, nutrição, saúde ambiental, nanomateriais, biotecnologia, etc. O quartzo puro é consumido, sob a forma de areias industriais (abrasivos, refratários, vidraçaria), para construção civil ou como cristal piezoelétrico, gerando produtos finais de uso em diferentes áreas, inclusive associadas com o famoso "vale do silício": elétrica, eletrônica (rádio, TV, disco), medicina, óptica, química, relojoaria, telecomunicações, novos materiais, fibra ótica, iluminação led, ultrassom e informática.

Quando em meios aquosos, nas diferentes condições termodinâmicas naturais do sistema água-sílica, possui comportamentos peculiares que caracterizam a sua gênese e evolução. Na hidrosfera, está presente em todos os tipos de corpos aquáticos e, em concentrações relativamente pequenas, como constituinte secundário dentre os demais solutos (Tabela 1).

Tabela 1. Conteúdo médio de Si em diferentes materiais/reservatórios. Segundo HEM (1989),

KRAUSKOPF \& LOAGUE (2003) e SHVARTSEV (2008a).

\begin{tabular}{lll}
\hline Material/Reservatório & $\mathrm{Unidade}$ & Valor \\
\hline Granito & $\mathrm{ppm}$ & 323000 \\
Basalto & $\mathrm{ppm}$ & 244000 \\
Xisto & $\mathrm{ppm}$ & 73000 \\
Arenito & $\mathrm{ppm}$ & 359000 \\
Solos & $\mathrm{ppm}$ & 330000 \\
Chuvas & $\mathrm{mg} / \mathrm{L}$ & 0,7 \\
Lagos alpinos & $\mathrm{mg} / \mathrm{L}$ & 0,8 \\
Oceanos & $\mathrm{mg} / \mathrm{L}$ & 2,9 \\
Águas de solos & $\mathrm{mg} / \mathrm{L}$ & 5,6 \\
Sangue humano & $\mathrm{mg} / \mathrm{L}$ & 6,1 \\
Rios tropicais & $\mathrm{mg} / \mathrm{L}$ & 9,5 \\
Rios temperados & $\mathrm{mg} / \mathrm{L}$ & 3,3 \\
Rios do mundo & $\mathrm{mg} / \mathrm{L}$ & 5,5 \\
Aquíferos do mundo & $\mathrm{mg} / \mathrm{L}$ & 8,4 \\
Aquíferos glaciais & $\mathrm{mg} / \mathrm{L}$ & 4,1 \\
Aquíferos tropicais & $\mathrm{mg} / \mathrm{L}$ & 9,8 \\
Aquíferos áridos & $\mathrm{mg} / \mathrm{L}$ & 14,6 \\
Aquíferos temperados & $\mathrm{mg} / \mathrm{L}$ & 6,2 \\
Aquíferos em & $\mathrm{mg} / \mathrm{L}$ & 7,1 \\
Aquíferos em & $\mathrm{mg} / \mathrm{L}$ & 37,4 \\
Altrabásicas & $\mathrm{mg} / \mathrm{L}$ & 25,6 \\
Aquíferos em riolitos & $\mathrm{mg} / \mathrm{L}$ & 3,7 \\
Aquíferos em granitos & 18,7 \\
\hline Aquíferos em arenitos & $\mathrm{mg} / \mathrm{L}$ & 11,9 \\
\hline & & 14,6 \\
\hline
\end{tabular}


Alguns fatores relacionados aos teores de Si dissolvido nas águas (raramente acima de $100 \mathrm{mg} / \mathrm{L}$ ) são: origem em minerais primários de difícil solubilização; mobilidade iônica menor que dos principais solutos presentes nas águas $\left(\mathrm{SiO}_{2}=0,2 \%\right.$, por exemplo, em comparação com $\mathrm{Cl}^{-}=100 \%$ ou $\mathrm{Ca}^{2+}=3 \%$ ); consumo pela biomassa; constante de dissociação alterada pela força iônica da água do mar ou presença de $\mathrm{CO}_{2}$; hidrólise relativamente lenta na faixa de $\mathrm{pH}$ naturalmente mais comum. Numa evolução normal do sistema água-rocha, grande parte do silício livre pela dissolução é prontamente absorvido na formação de argilas resultantes das interações entre minerais secundários (HEM, 1989; SZIKSZAY, 1993; SHVARTSEV, 2008a).

As águas superficiais e as de aquíferos rasos possuem concentrações e formas de silício influenciadas pela temperatura atmosférica, presença de $\mathrm{CO}_{2}$, sílica livre nos solos, salinidade, matéria orgânica, tempo de contato e distância percorrida. Em especial, o calor aumenta sua solubilidade em regiões de climas tropicais (Tabela 1) e, numa mesma região, durante as estações mais quentes do ano (TARDY, 1971). Nas águas subterrâneas, o teor de Si costuma ser mais elevado, ao ponto deste aspecto ser utilizado para indicar a autenticidade de uma água mineral natural, bem como distingui-la de uma água superficial (BELTON et al., 2012).

Nas águas subterrâneas, os diferentes litotipos afetam a presença do Si dissolvido, por exemplo: nas rochas cristalinas, sua hidrólise é menor que nas sedimentares arenosas, havendo maior dependência da participação do $\mathrm{CO}_{2}$; os feldspatos alcalinos nos granitos (e gnaisses) implicam em concentrações entre 4 e 10 mg/L de Si; nos dioritos, ocorre principalmente como $\mathrm{SiO}_{2}$ coloidal e pouco $\mathrm{H}_{4} \mathrm{SiO}_{4}$; nos basaltos, são comuns concentrações maiores que nos granitos, em torno de $20 \mathrm{mg} / \mathrm{L}$; nos micaxistos, a concentração média é de $9 \mathrm{mg} / \mathrm{L}$ e nos arenitos de 12 mg/L (SZIKSZAY, 1993). A solubilidade da sílica nas águas provenientes de rochas ultrabásicas é mais elevada devido à menor salinidade do meio (Tabela 1).

Análises espectroscópicas indicaram 20 espécies distintas de silicatos em águas naturais (EXLEY \& SJÖBERG, 2014). Podem ocorrer como nanopartículas dispersas e sob a forma iônica dissolvida, sendo difícil a distinção devido ao seu comportamento atípico como um eletrólito (neutralidade de carga) e, também, às propriedades incomuns para um coloide (HEM, 1989). Em condições normais, na maioria das águas, a espécie predominante de $\mathrm{Si}$ ocorre como ácido ortossilícico $\left(\mathrm{H}_{4} \mathrm{SiO}_{4}\right)$ e, mais raramente, como ácido metassilícico $\left(\mathrm{H}_{2} \mathrm{SiO}_{3}\right)$. A forma coloidal não iônica costuma predominar em águas superficiais e águas dispersas nos solos, principalmente na presença de matéria orgânica. A polimerização da sílica pelo rápido resfriamento das águas de fontes termais resulta, comumente, no predomínio composicional sob a forma de precipitados coloidais nestas ocorrências (DOBRZYŃSKI \& EXLEY, 2010).

\section{Hidrogeoquímica da sílica}

Nos processos geológicos, o estado de equilíbriodesequilíbrio do sistema águas-rochas-gases-matérias orgânicas (vivas e não vivas) direciona a formação diversificada dos tipos geoquímicos, hidroquímicos e de minerais secundários associados aos fluidos mantélicos, magmáticos, hidrotermais, depósitos de minérios e de intemperismo (SHVARTSEV, 2008b).

Em condições normais, a solubilidade da $\mathrm{SiO}_{2}$, sob a forma de quartzo, é de $6,5 \mathrm{mg} / \mathrm{L}$, podendo aumentar de acordo com a composição, estrutura e granulometria $\left(<10^{-4}\right.$ $\mathrm{cm}$ ) dos diferentes minerais silicátios, por exemplo, a sílica amorfa pode solubilizar em até $115 \mathrm{mg} / \mathrm{L}$ (SZIKSZAY, 1993). Como principal reação de dissolução dos silicatos, ocorre inicialmente a hidrólise, quando as superfícies de contato dos minerais silicáticos desequilibram-se em suas valências, permitindo o início da hidratação. Em condições normais, esta hidratação transforma a $\mathrm{SiO}_{2}$ em $\mathrm{H}_{4} \mathrm{SiO}_{4}$ e, em $\mathrm{pH}$ acima de 9, também para as formas de $\mathrm{SiO}_{3}{ }^{2-}, \mathrm{Si}(\mathrm{OH})_{6}{ }^{2-}$ ou $\mathrm{H}_{3} \mathrm{SiO}_{3}{ }^{-}$. Independente do tipo da rocha de origem (não carbonáticas), as águas onde o pH aumenta de 5 para 7 possibilitam uma maior concentração de sílica em solução. A solubilidade da sílica é constante na faixa de $\mathrm{pH}$ 2-9, onde o $\mathrm{pH}$ ideal para a precipitação da sílica como coloide é próximo de 4,5 ; em $\mathrm{pH} 8$, existe a tendência de ocorrer como molécula dispersa (SJOBERG, 1996). Quando em meios de $\mathrm{pH}$ extremos, ácido ou principalmente básico, seu potencial de dissolução sofre aumento significativo, por exemplo na nascente de água fria de Aqua de Ney/California/ EUA, que contém $\sim 1870 \mathrm{mg} / \mathrm{L}$ de Si $(\mathrm{pH}=11,6)$ (FETH et al., 1961).

$\mathrm{O} \mathrm{CO}_{2}$ promove a transição da sílica em solução. A presença de alumínio e fluoreto na água pode causar a desintegração e retenção da sílica solúvel. A presença do alumínio, mesmo que em baixa concentração, pode aumentar, em muito, a quantidade de sílica precipitada sob a forma coloidal (GIMENO et al., 2009).

A dependência da composição dos cátions sobre a química dos aluminossilicatos é mais claramente manifestada nas águas mais frescas ou de circulação mais rápida. Em soluções alcalinas, especialmente as contendo sais de sódio, apesar do aumento da salinidade ser inversamente proporcional ao conteúdo de sílica, pode ocorrer aumento da solubilidade da sílica na água em até 50 vezes (com o $\mathrm{NaHCO}_{3}$ e $\mathrm{NaOH}$ ) ou mesmo até 100 vezes (com o $\mathrm{NaCl}$ ) (BRICKER, 1967).

Porém, o aumento de temperatura é o fator que mais influencia na solubilidade da sílica (TÖLGYESSY, 1993), explicando as elevadas concentrações ocorrendo nas águas subterrâneas geotermais de gêiseres em Yellowstone/EUA ( 690 mg/L de Si), nas nascentes termais em Nevada/EUA ( 490 mg/L de Si) ou em poços de Nesjavellir/ISL ( 320 mg/L de Si), onde são atingidas temperaturas de até $300{ }^{\circ} \mathrm{C}$ (DOUCET et al., 2001). 
A termodinâmica do ambiente externo afeta a evolução dos sistemas água-rocha abaixo de $400^{\circ} \mathrm{C}$ e a menos de $200 \mathrm{~m}$ de profundidade, a composição dos materiais envolvidos, as relações com agentes da superfície no decorrer do tempo geológico e o comportamento do fluxo de água. Porém, especialmente ao ciclo hidrogeológico, são ainda mais relevantes o tempo de duração das interações e as reações com os minerais secundários recém-formados, que geralmente são aluminossilicatos (SHVARTSEV, 2008b).

Diante da diversidade dos minerais silicáticos, a maioria dos elementos presentes é solubilizada antes, ou mais rapidamente, que o $\mathrm{Si}$ e o $\mathrm{Al}$, originando recristalização de minerais secundários, por exemplo, os hidróxi-aluminossilicatos, depois os argilominerais endógenos, que absorvem em suas cristalizações grande parte dos íons de silício disponíveis, que se fixam em suas estruturas ou precipitam-se, sem quase restar na fase aquosa (DOUCET et al., 2001).

A magnitude destes processos é observada por representar três dentre os sete tipos geoquímicos dominantes de águas subterrâneas: alumínio-silício, silício-sódio e ácido silício-orgânico. A sua evolução, denominada "reação reversa de alteração", envolve o equilíbrio natural de três argilominerais principais: caulinita, montmorilonita e ilita. A liberação de gás carbônico destas reações e a composição destes minerais secundários endógenos proporcionam nova dinâmica geoquímica nestes sistemas (BRICKER, 1967; SHVARTSEV, 2008b). Este processo é, de tal maneira, comum e com parâmetros nitidamente definidos, que fundamenta algumas classificações do intemperismo através dos tipos de minerais recémformados, controlados pela intensidade da remoção da sílica, alumínio e das bases durante a decomposição da rocha inicial (TARDY, 1971).

\section{Ciclo biogeoquímico da sílica}

Embora a sílica esteja dentre os oito mais importantes componentes biologicamente ativos na dinâmica dos ciclos biogeoquímicos globais, no geral, admite-se ser o mais desconhecido deles. Em seu ciclo é observada a influência predominante dos processos oceânicos devido ao volume total envolvido e o maior tempo de permanência da sílica dissolvida em suas águas ( 8000 anos), por meio de mecanismos evolutivos bem mais lentos que os observados nas águas continentais, especialmente as superficiais.

Resumidamente, os principais caminhos do ciclo biogeoquímico da sílica são: nos continentes, ocorre sua dissolução através do intemperismo das rochas ou pelas alterações hidrogeológicas; a seguir, este material é transportado até os oceanos, onde então é assimilado na fotossíntese por organismos marinhos, que, ao morrerem, depositam Si nos fundos oceânicos, o qual retorna aos continentes após sua diagênese como rochas sedimentares na escala de tempo geológico.

A sílica também está presente nos vegetais em quantidades equivalentes aos elementos essenciais cálcio, magnésio e fósforo. Não há nenhum composto de Si-C, $\mathrm{Si}-\mathrm{N}$ ou $\mathrm{Si}-\mathrm{O}-\mathrm{C} / \mathrm{N}$ em qualquer processo biológico natural. $\mathrm{O} \mathrm{Si}(\mathrm{OH})_{4}$ é um monômero neutro, em quase todas as condições fisiológicas possíveis. Como molécula, seu análogo mais próximo em sistemas biológicos é a água. E, sob esta sua forma iônica mais simples, solúvel e comumente presente nas águas naturais, a sílica é absorvida por grande quantidade de organismos como diatomáceas, radiolárias, esponjas e, até mesmo, plantas superiores. Também é um constituinte fundamental nos fenômenos de biomineralização, onde a capacidade dos seres vivos em cristalizar novos minerais associa-se à origem da vida no planeta, conforme identificado em fósseis das primeiras cianobactérias contendo o silício junto ao cálcio (MATSKO et al., 2011; BELTON et al., 2012).

As relações do silício com o alumínio, terceiro elemento mais abundante na crosta terrestre, são importantes para a própria evolução da vida na Terra. Inicialmente, por ocorrerem juntos como constituintes principais dos também abundantes argilominerais hidróxi-aluminossilicatos, que, para o $\mathrm{Al}$, representam grande parte de sua origem disponível ao ciclo litosférico. Embora todas as espécies destes minerais possuam atividades biológicas praticamente nulas, participam de maneira fundamental na maior parte dos processos biogeoquímicos e algumas reações podem transformá-los em substâncias contendo o alumínio numa forma com maior bioatividade e potencial biodisponível. Uma vez que já é bem reconhecida a toxicidade do $\mathrm{Al}$, mesmo em baixas concentrações, o enfoque apresentado possui algum significado (EXLEY, 2012).

Em zonas tropicais úmidas, certas características biológicas são controladas por um particular processo de intemperismo que, decompondo diversificados tipos de rochas, resultam normalmente num mesmo material argiloso de cor avermelhada e predominância de ferro e alumínio, devido a suas menores reatividades nestes ambientes. Assim, solos e águas superficiais em clima tropical costumam ser ácidos, também devido à ausência de cálcio e outros metais capazes de neutralizar os ácidos orgânicos (HAZEN \& SVERJENSKY, 2010).

Tais controles geoquímicos das paisagens tropicais úmidas são determinantes na bioquímica destes ecossistemas, sendo dignos de nota (PEREL'MAN, 1962, 1986): a explicação mais aceita atualmente sobre a exuberante coloração de seus papagaios, beija-flores e outras aves tropicais, resultante de uma alimentação mais rica em alumínio que a de seus parentes habitantes de latitudes temperadas; a biocristalização de mineral silicático amorfo, de características muito similares à pedra preciosa opala, originada por atividades vegetais que ocorrem em árvores especialmente adaptadas pela evolução em meio típico de umidade, calor e lamas tropicais. 


\section{Bioatividade do silício}

Apesar de ainda não muito conhecidos, os benefícios do Si à saúde humana tiveram seus primeiros estudos no século XVI. São encontradas citações de suas formas dissolvidas em águas nos tratados fundamentais da medicina e da farmacopeia do século XIX, sendo célebre o comentário de Louis Pasteur: "os efeitos do ácido silícico estão destinados a desempenhar papel da maior relevância nas principais terapias". Trabalhos experimentais iniciados no século $\mathrm{XX}$ reforçaram a sua importância, associando um melhor e mais saudável desenvolvimento dos seres vivos habitando ambientes enriquecidos em sílica (SCHEER, 1997; EXLEY, 2012).

Tradicionais SPAs franceses (Bains-les-Bains, Barbotan-les Thermes, Luxeuil-les-Bains e Neyrac-les-Bains) e da região de Saratoga/EUA (Red Springs) são conhecidos como de águas silicatadas ou silicosas, sendo suas fontes com propriedades terapêuticas utilizadas há muitas décadas em banhos, ingestões, inalações ou mesmo como colírio (BAUDISCH, 1943; LACROIX \& ABOYANS, 2005).

Atualmente, mesmo classificado como elemento traço ou micronutriente, é reconhecida internacionalmente a recomendação dietética de $35-45 \mathrm{mg} /$ dia de $\mathrm{Si}$, para se evitar sintomas de sua deficiência. Por exemplo, observa-se nos EUA que 10 milhões de pessoas, acima dos cinquenta anos, apresentam osteoporose, enquanto outras 34 milhões exibem baixa massa óssea, especialmente as mulheres (PRICE et al., 2012).

O Si compreende apenas $0,026 \%$ da massa total do corpo humano e ocorre, naturalmente, em alimentos sob a forma de dióxido de silício e outros silicatos. Uma das melhores fontes nutricionais de Si ocorre pela ingestão de bebidas, especialmente em sua forma mais biodisponível, quando dissolvido naturalmente nas águas minerais (PRESCHA et al., 2011). Assim, sua biodisponibilidade para o consumo humano equivale entre 50 a $86 \%$ do $\mathrm{Si}$ ingerido e, tipicamente, contribuem no mínimo com $20 \%$ de seu consumo total cotidiano (MATSKO et al., 2011).

A presença de Si coloidal nas águas minerais costuma desempenhar papel importante no controle da disponibilidade biológica tóxica do alumínio, bem como no aumento da eficácia hidroterápica, melhoria da capacidade de absorção fisiológica dos alimentos. A sua interação com outros oligoelementos potencializa a bioatividade de outros elementos, por exemplo, do molibdênio (JUGDAOHSINGH et al., 2002; JUGDAOHSINGH, 2007).

Não há consenso quanto ao teor mínimo de Si dissolvido para uma água ser considerada minero-medicinal silicatada, pois, observa-se: Ucrânia $=25,3 \mathrm{mg} / \mathrm{L}$; Saratoga Springs $(\mathrm{EUA})=27,3 \mathrm{mg} / \mathrm{L}$; estâncias francesas = 35 mg/L (BAUDISCH, 1943; LACROIX \& ABOYANS, 2005). Alguns trabalhos com metodologia clínica abordaram a potencial atividade biológica eficaz do Si em aplicações terapêuticas. Por exemplo, águas silicatadas de Fiji (Japão), com 39,7 mg/L de Si, têm sido indicadas para ingestão e banhos para doenças ósseas, musculoesqueléticas e metabólicas, especialmente para mulheres (LI et al., 2010). Estudo realizado com água mineral da Fonte Tersinka, em Kuznetsk (Rússia), indicou atividade terapêutica com $37 \mathrm{mg} / \mathrm{L}$ de Si, por intermédio de inalação de aerossóis por pacientes com sintomas clínicos de inflamação das vias respiratórias, secreção nasal, bronquite crônica e asma brônquica. Por meio da ingestão destas mesmas águas silicatadas, observaram-se alterações hepáticas estruturais adaptativas a nível celular e sub-celular, bem como mudanças físicas da bioenergia celular, relacionadas com os tamanhos e quantidades de suas ligações ultra-estruturais (KOROLEV \& PANOVA, 1994; SMIRNOVA et al., 2003).

Para observação dos benefícios à saúde, devido o consumo cotidiano de águas contendo $\mathrm{Si}$, estudos epidemiológicos, em diversas regiões dos EUA, indicaram a existência de correlação entre a potabilidade de águas com teores de 8-15 mg/L de Si e uma menor taxa de mortalidade devido a doenças coronárias e problemas de coração na população. Na República Tcheca, foram realizados experimentos farmacológicos in vitro em voluntários que consumiram, num longo prazo, a água mineral da Fonte Trenčianske, em Teplice, com 18,9 mg/L de $\mathrm{Si}$, os quais indicaram efeito inibidor da peroxidação lipídica como propriedade antioxidante (PRESCHA et al., 2011).

Como evidência experimental do poder de absorção e biodisponibilidade do Si em águas minerais, comparativamente à de outros alimentos, cita-se pesquisa comparativa entre dezenas de alimentos, onde análises da urina excretada após seis horas de sua ingestão, realizadas em milhares de voluntários, demonstraram o maior teor de Si obtido a partir do consumo de meio litro de água mineral contendo $14,5 \mathrm{mg} / \mathrm{L}$ de Si (da marca Volvic/França) (GILLETTE-GUYONNET et al., 2005).

Estudo epidemiológico foi conduzido em cinco regiões francesas, do qual participaram 7598 mulheres com mais de 75 anos de idade, divididas em 15 diferentes grupos, as quais ingeriram, diariamente, um determinado tipo de água (8 minerais engarrafadas e 7 potáveis públicas) de teor conhecido de $\mathrm{Si}$, $\mathrm{Al}$ e $\mathrm{Ca}$ (GILLETTE-GUYONNET et al., 2005; RONDEAU et al., 2009; DOMINGO et al., 2011). A metodologia utilizada (EPIDOS) é reconhecida para determinação do fator de risco associado à doença de Alzheimer e osteoporose. A avaliação do Al foi fundamentada em estudos que inferiram sua toxicidade como causa do Alzheimer e a observação de que Ca é benéfico para a prevenção da osteoporose em idosas.

Assim, dentre as principais indicações terapêuticas e de cosmetologia do Si estão (BAUDISCH, 1943; IOM, 1980; KOROLEV \& PANOVA, 1994; SCHEER, 1997; LAGUARDA, 2002; SMIRNOVA et al., 2003; LACROIX \& ABOYANS, 2005; LI et al., 2010; DROBNIK et al., 2011): para a saúde de idosos- ação anti-inflamatória, antitóxica, diabetes, disfunção do metabolismo e sistema imunológico, combate de irritações e afecções cutâneas 
ou doenças dermatológicas pruriginosas; em cosmetologia- emoliente, sedante, anti-inflamatória e aumento da elasticidade da pele e colágeno, aplicações externas ou tópicas; em balneoterapia- potencializa a adsorção cutânea do ácido silícico, explicada pela necessidade cutânea e a fina película formada por componentes coloidais de ácido monossilícico presente nas águas; mineralização dos ossos, endurecimento do tecido conjuntivo, prevenção da osteoporose, função nutricional óssea, auxilia na reparação dos tecidos, tratamento de doenças ósseas e musculoesqueléticas, importante no metabolismo, manutenção do tecido ósseo, formação, crescimento e calcificação dos ossos e cartilagens, influencia na calcificação, agente de reticulação do tecido conjuntivo; sua deficiência nutricional pode ocasionar diminuição do crescimento esquelético; impede as alterações nos neurônios induzidas pela toxicidade do $\mathrm{Al}$, proteção contra a arteriosclerose e doença de Alzheimer; inibidor da peroxidação lipídica in vitro e ação antioxidante; aumento da permeabilidade das paredes dos vasos sanguíneos e reduz o risco de doenças cardíacas; importante nutriente energizante; eficácia terapêutica através da inalação de aerossóis por pacientes com sintomas clínicos de inflamação das vias respiratórias, secreção nasal, bronquite crônica e asma brônquica; alterações hepáticas estruturais adaptativas a nível sub-celular, mudanças fásicas da bioenergia celular, relacionadas com os tamanhos e quantidades de suas ligações ultra-estruturais, melhorando a função hepática; doenças ginecológicas; benefícios para o fortalecimento e crescimento da pele, unhas, cabelo e fibras colágenas; benefícios par os olhos, como colírio; papel bioquímico no mecanismo de homeostasia, absorção intestinal e excreção urinária, evitando doenças gastro-intestinais e compensando danos causados pelo consumo excessivo de álcool.

\section{5 Águas silicatadas no Brasil}

O Código de Águas Minerais do Brasil (Decreto-lei No. 7841 de 8 de agosto de 1945) estabelece que as águas minerais deverão ser classificadas de acordo com o elemento predominante, íons ou substâncias dignas de nota (Brasil, 1945). Uma vez que a classificação de água mineral silicatada (ou silicática) não está prevista em legislação brasileira, exemplos de outros países serviram para a definição dos parâmetros iniciais. Assim, para sugerir possíveis aplicações no Brasil em crenoterapia, hidro-balneoterapia ou consumo dietético, foram consultadas legislações similares de outros países e publicações técnico-científicas sobre o assunto. As palavras-chave adotadas foram: silicon OR siliceous AND water OR mineral water AND spa OR hydrotherapy OR balneotherapy OR crenology. Diferentes bancos de dados foram utilizados, dentre eles scholar.google. com e sciencedirect.com. Com isto, foi adotado o valor de $37 \mathrm{mg} / \mathrm{L}$ de Si, neste trabalho, como o mínimo para uma água silicatada, enquanto que o valor mínimo de bioatividade nutricional correspondeu a 11,2 mg/L de Si. Os fatores de conversão dos compostos de silício são: $1 \mathrm{mg} / \mathrm{L}$ de $\mathrm{SiO} 2=0,47 \mathrm{mg} / \mathrm{L}$ de $\mathrm{Si}=1,3 \mathrm{mg} / \mathrm{L}$ de H2SiO3.

A compilação de dados para as águas brasileiras foi realizada buscando o maior número possível de informações disponíveis, além dos teores de Si, isto é, formas de jazimento (nascente, poço ou poço jorrante), litologia, coordenadas geográficas e análises hidroquímicas (STDsólidos totais dissolvidos, temperatura, $\mathrm{pH}$, vazão, etc..). As palavras-chave nesta consulta foram: água OR fonte AND mineral OR medicinal OR sílica AND composição OR hidroquímica OR análise. Dentre os bancos de dados utilizados citam-se google.com.br, scholar.google.com. br, scielo.org, periodicos.capes.gov.br, sistemas.dnpm. gov.br/ sighidro/, siagasweb.cprm.gov.br e bancos de teses e monografias de universidades brasileiras.

Foi possível localizar 322 ocorrências de águas subterrâneas contendo dados de silício, cuja concentração média correspondeu a 26,4 mg/L (LAZZERINI, 2013). Este valor é superior à média mundial de 10,1 mg/L para 2500 análises de águas engarrafadas, conforme encontrado em mineralwaters.org. As legislações de outros países para a classificação de águas minerais silicatadas sugerem, como teores mínimos: Japão=17,9 $\mathrm{mg} / \mathrm{L}$, Rússia=23,4 mg/L, Polônia=25,3 mg/L, Espanha= $14,1 \mathrm{mg} / \mathrm{L}, \mathrm{Cuba}=18,7 \mathrm{mg} / \mathrm{L}, \mathrm{EUA}=45,1 \mathrm{mg} / \mathrm{L}$ (FAGUNDO et al., 2001).

No Brasil, foram encontrados poucos trabalhos sobre bioatividade ou indicação terapêutica de águas silicatadas, sendo relacionados à propriedade sedante e emoliente, de interesse em dermatopatias pruriginosas (MOURÃO, 1992; FRANGIPANI et al., 1995). O maior valor de Si encontrado na compilação realizada foi na Ilha de Marajó/PA, constituindo o poço PE-31 com 80 $\mathrm{m}$ de profundidade e concentração de $462,1 \mathrm{mg} / \mathrm{L}$ (Tabela 2). Na Fig. 1 estão representadas 57 ocorrências de águas subterrâneas silicatadas no Brasil. A Fig. 2 ilustra o diagrama de Piper para 207 ocorrências de águas silicatadas, enquanto que na Fig. 3 consta o diagrama Durov para 57 ocorrências.

Tabela 2. As dez principais ocorrências de Si em águas subterrâneas do Brasil. Valores em mg/L.

\begin{tabular}{lll}
\hline Município & Estado & Valor \\
\hline Santa Cruz do Ararí & PA & 462,1 \\
Cachoeira do Ararí & PA & 433,8 \\
Lagoa Seca & PB & 285,0 \\
Soure & PA & 279,1 \\
Nhecolandia-Corumbá & MS & 274,0 \\
Paraguaçu Paulista & SP & 100,0 \\
Barra de Santa Rosa & PB & 97,0 \\
Marília & SP & 95,6 \\
Brejo da madre de deus & PE & 81,2 \\
Cambará & PR & 74,9 \\
\hline
\end{tabular}




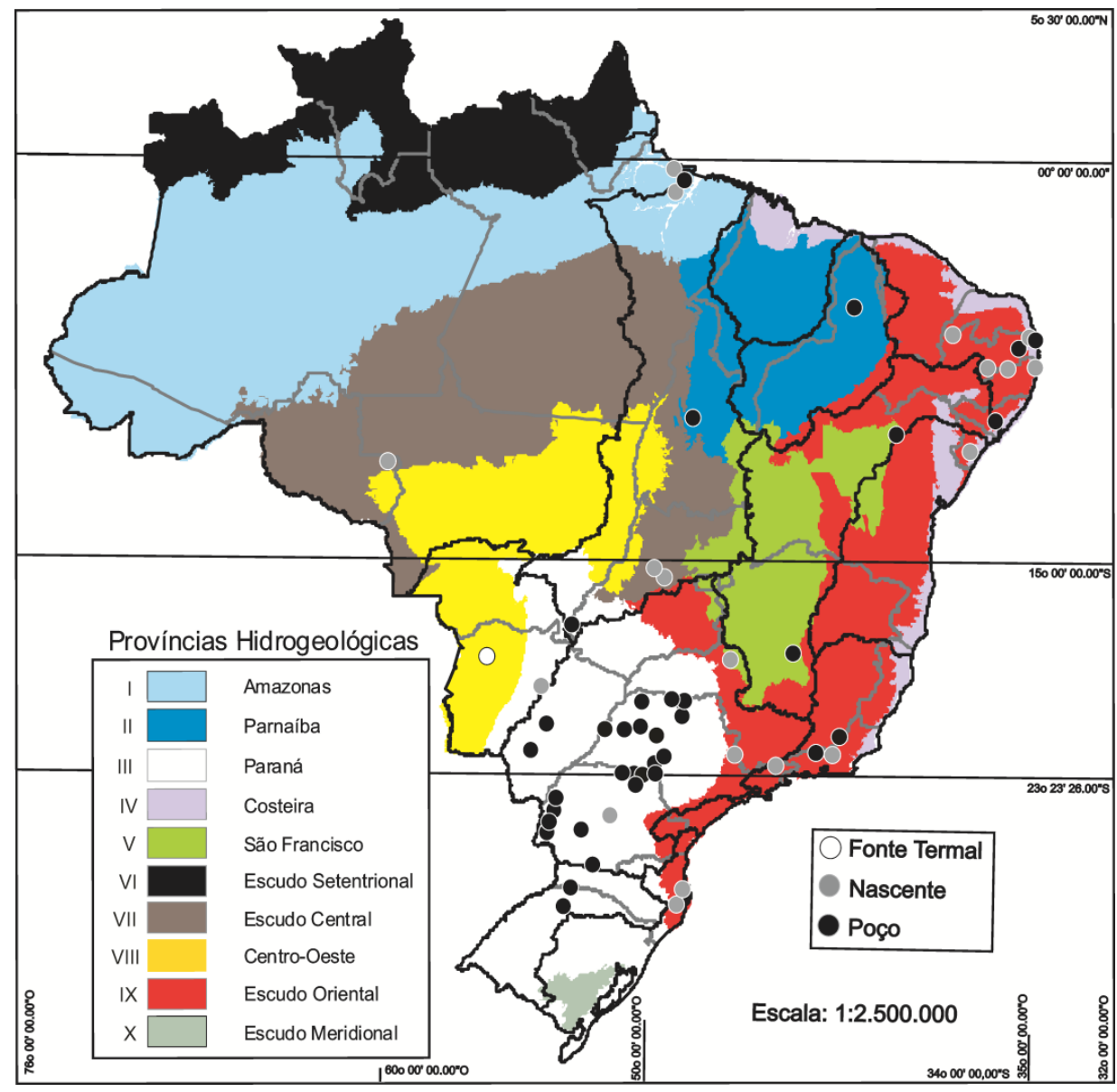

Figura 1- Principais ocorrências de águas subterrâneas silicatadas no Brasil.

\section{Piper Diagram}

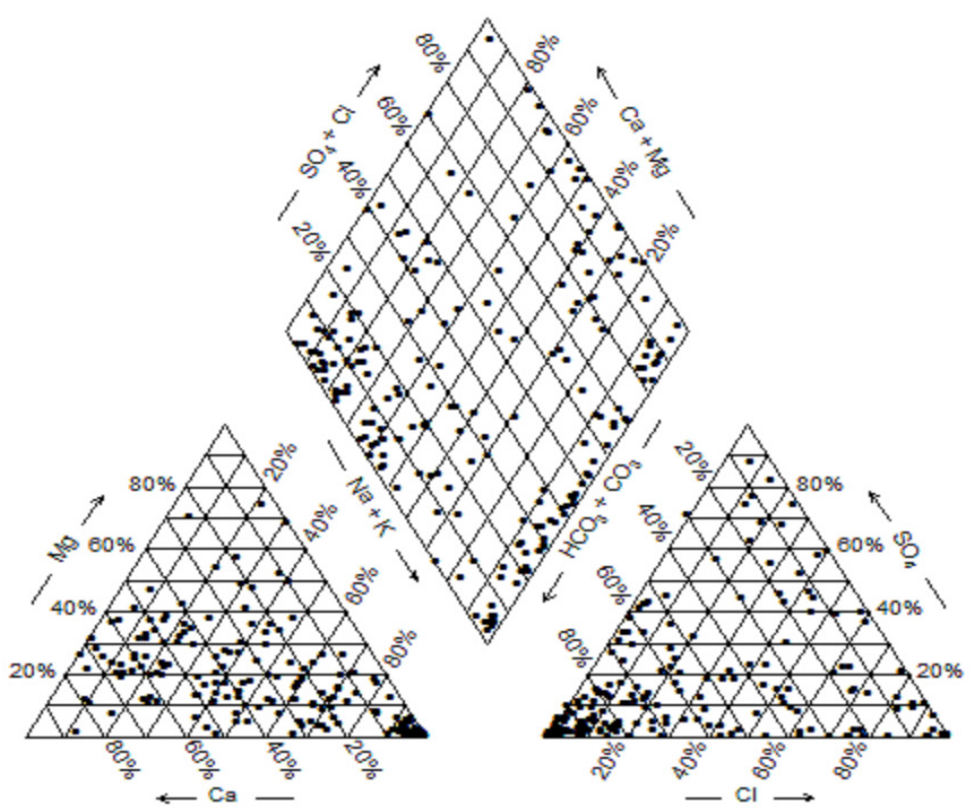

Figura 2- Diagrama de Piper para 207 ocorrências de águas subterrâneas silicatadas no Brasil. 


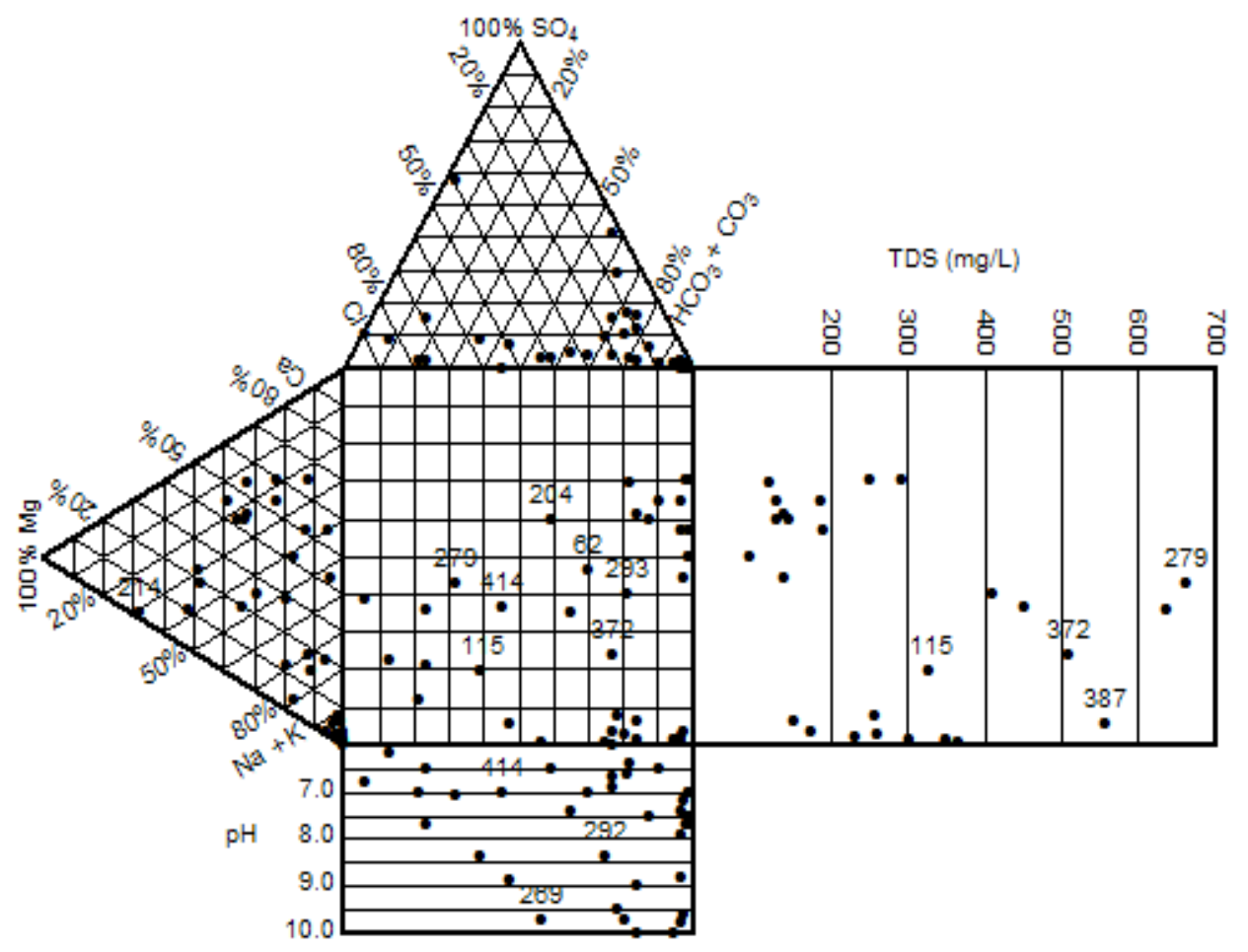

Figura 3- Diagrama Durov para 57 ocorrências de águas subterrâneas silicatadas no Brasil

Nas águas que percolam rochas compostas por minerais pouco reativos, principalmente quartzosos ou sílicas amorfas, a dissolução dos aluminossilicatos torna-se inexpressiva, permitindo o incremento das concentrações e relações iônicas favoráveis ao silício em solução. A relação iônica $\mathrm{SiO}_{2} / \mathrm{Na}$ pode não ser tão grande quando ocorre influência marinha, por exemplo arenitos das províncias costeiras ou granito-gnaisses do escudo oriental próximos ao litoral. Mas, quando ocorrem fluxos mais profundos em aquíferos deste mesmo tipo litológico, a relação iônica $\mathrm{SiO}_{2} / \mathrm{Na}$ pode ser mais alta, como se observa em arenitos da bacia Amazônica (BERTOLO et al., 2007).

As rochas carbonatadas costumam possuir baixas concentrações de sílica, à exceção da Formação Corumbataí na bacia sedimentar do Paraná, devido à presença de bancos de minerais silexíticos interestratificadas. Nesta mesma bacia sedimentar, é reconhecida a elevada presença de Si nas águas subterrâneas, provavelmente relacionada à ausência da influência marinha, de carbonatos ou sulfatos, nas áreas de recarga dos aquíferos e da existência de basaltos naquele sistema.

\section{Conclusão}

Nas localidades das fontes hidrominerais, as influências fisiológicas começam pelos aspectos de beleza e preservação da natureza ou paisagismo urbano, conhecimento dos recursos naturais com propriedades terapêuticas, da infra-estrutura favorável e bem adaptada para estes usos, bem como do histórico nas práticas e pesquisas médicas existentes. Outro aspecto ambiental de importância no conjunto de bioatividades potencialmente terapêuticas, relacionadas às fontes hidrominerais, são os fatores climáticos, inicialmente não poluídos e controlados basicamente pelas latitudes, altitudes e condicionantes macrogeográficos. As informações adquiridas, neste trabalho sobre a presença de silício nas águas, contribuem com avanços significativos sobre o tema, possibilitando que vários enfoques possam ser desenvolvidos, tais como: incremento do inventário das ocorrências de interesse, levantamento de parâmetros ambientais regionais e locais, realização de estudos comparativos de bioatividades ou aplicações terapêuticas, aprimoramento de análises de substâncias coloidais e diferentes formas do silício dissolvido e aprofundamento de estudos sobre a bioatividade do silício em crenoterapias, balneoterapias e nutrição.

\section{Referências}

BAUDISCH, O. The importance of trace elements in biologic activity. Journal of the American Medical Association, v. 123, n. 15, p. 959-966, 1943.

BELTON, D. J.; DESCHAUME, O.; PERRY, C. C. An overview of the fundamentals of the chemistry of silica with relevance to biosilicification and technological advances. The FEBS Journal, v. 279, p. 1710-1720, 2012. 
BERTOLO, R. A.; HIRATA, R.; FERNANDES, A. Hidrogeoquímica das águas minerais envasadas do Brasil. Revista Brasileira de Geociências, v. 37, n. 3, p. 515-529, 2007.

BRASIL. Código de Águas Minerais: Decreto-Lei No. 7841 de 08/08/1945. Rio de Janeiro: Ministério de Minas e Energia-MME, 1945.

BRICKER, O. P. Cations and silica in natural waters: control by silicate minerals. Int. Ass. Set. Hydrol. Spec. Pub., v. 78, p. 110-119, 1967.

DOBRZYŃSKI, D.; EXLEY, C. Solubility control and therapeutic potential of silicon in curative mineral waters of the Sudetes Mountains, Poland. Acta Balneologica, v. LII, n. 4, p. 296-304, 2010.

DOMINGO, J. L.; GÓMEZ, M.; COLOMINA, M. T. Oral silicon supplementation: an effective therapy for preventing oral aluminum absorption and retention in mammals. Nutrition Reviews, v. 69, n. 1, p. 41-51, 2011.

DOUCET, F. J.; SCHNEIDER, C.; BONES, S. J.; KRETCHMER, A.; MOSS, I.; TEKELY, P.; EXLEY, C. The formation of hydroxyaluminosilicates of geochemical and biological significance. Geochimica et Cosmochimica Acta, v. 65, n. 15, p. 2461-2467, 2001.

DROBNICK, M.; LATOUR, T.; SZIWA, D. The elements of specific biological activity in therapeutic waters in Polish health resorts. Journal of Elementology, v. 16, n. 4, p. 525-533, 2011.

EXLEY, C. Reflections upon and recent insight into the mechanism of formation of hydroxyaluminosilicates and the therapeutic potential of silicic acid. Coordination Chemistry Reviews, v. 256, p. 82-88, 2012.

EXLEY, C.; SJÖBERG, S. Silicon species in seawater. Spectrochimica Acta Correspondence (Part A) Molecular and Biomolecular Spectroscopy, v. 117, p. 820-821, 2014.

FAGUNDO, J. R.; CIMA, A.; GONZÁLEZ, P. Revision Bibliografica sobre Classificación de las Aguas Minerales y Mineromedicinales. Havana: Centro Nacional de Termalismo "Víctor Santamarina", 27 p. 2001.

FETH, J. H.; ROGERS, S. M.; ROBERSON, C. E. Aqua de Ney - California: a spring of unique chemical character. Geochimica et Cosmochimica Acta, v. 22, n. 2, p. 75-77, 1961.
FRANGIPANI, A.; CERIANI, C.; FLORA, F. M.; FILHO, M. U.; SIMÕES, R. A. P.; ALVISI, T. C. Termalismo no Brasil. Belo Horizonte: Sociedade Brasileira de Termalismo, Seção de Minas Gerais, 112 p. 1995.

GILLETTE-GUYONNET, S.; ANDRIEU, S.; NOURHASHEMI, F.; DE LA GUÉRONNIÈRE, V.; GRANDJEAN, H.; VELLAS, B. Cognitive impairment and composition of drinking water in women: findings of the EPIDOS Study. American Journal of Clinical Nutrition, v. 81, p. 897-902, 2005.

GIMENO, M. J.; AUQUÉ, L. F.; GÓMEZ, J. B.; ACERO, P. Water-rock interaction modelling and uncertainties of mixing modelling, Site descriptive modelling, SDM-Site Laxemar. Stockholm: Swedish Nuclear Fuel and Waste Management Co., 365 p. 2009.

HAZEN, R. M.; SVERJENSKY, D. A. Mineral Surfaces, Geochemical Complexities and the Origins of Life. Cold Spring Harbor Perspectives in Biology, v. 2, n. 5, p. 1-21, 2010.

HEM, J. D. Study and Interpretation of the Chemical Characteristics of Natural Waters. $3^{\text {rd }}$ ed. Water Supply Paper, n. 2254. Washington: U.S. Geological Survey, 263 p. 1989.

IOM (Institute of Medicine). The Contribution of Drinking Water to Mineral Nutrition in Humans. In: IOM (Institute of Medicine) ed. Drinking Water and Health: Safe Drinking Water Committee Board on Toxicology and Environmental Health Hazards National Research Council, v. 3, 415 p. 1980.

JUGDAOHSINGH, R. Silicon and bone health. Journal of Nutrition Health Aging, v. 11, n. 2, p. 99-110, 2007.

JUGDAOHSINGH, R.; ANDERSON, S. H. C.; TUCKER, K. L.; ELLIOTT, H.; KIEL, D. P.; THOMPSON, R. P. H.; POWELL, J. J. Dietary silicon intake and absorption. American Journal of Clinical Nutrition, v. 75, n. 5, p. 887-893, 2002.

KOROLEV, I. N.; PANOVA, L. N. The ultrastructural reactions of cells to the action of potable silicon-containing waters. Vopr Kurortol Fizioter Lech Fiz Kult, v. 5, p. 36- 
38, 1994.

KRAUSKOPF, K. B.; LOAGUE, K. Environmental Geochemistry. $3^{\text {rd }}$ ed. p. 519-545, 2003.

LACROIX, P.; ABOYANS, V. Thermalisme et médecine vasculaire: Thermatology and vascular medicine. EMC-Cardiologie Angéiologie, v. 2, p. 344-350, 2005.

LAGUARDA, S. V. Balneoterapia en Dermatología. Medicina Estetica, v. 3, p. 1-4, 2002.

LAZZERINI, F. T. Fontes Hidrominerais do Brasil: Componentes Naturais Biologicamente Ativos. Tese (Doutorado em Geologia Regional) -UNESP, Rio Claro. 388 pp. 2013.

LI, Z.; KARP, H.; ZERLIN, A.; LEE, T. Y.; CARPENTER, C.; HEBER, D. Absorption of silicon from artesian aquifer water and its impact on bone health in postmenopausal women: a 12 week pilot study. Nutrition Journal, v. 14, p. 9-44, 2010.

MATSKO, N. B.; ZNIDARŠIC, N.; LETOFSKY-PAPST, I.; DITTRICH, M.; GROGGER, M.; ŠTRUS, J.; HOFER, F. Silicon: the key element in early stages of biocalcification. Journal of Structural Biology, v. 174, p. 180-186, 2011.

MOURÃO, B. M. Medicina Hidrológica: moderna terapêutica das águas minerais e estâncias de cura. Poços de Caldas: PRIMA Promotora de Informações Ltda, 733 p. 1992.

PEREL'MAN, A. I. Geochemical barriers: theory and practical applications. Applied Geochemistry, v. 1, p. 669-680, 1986.

PEREL'MAN, A. I. Geochemistry of ancient landscapes. International Geology Review, v. 4, n. 3, p. 253-262, 1962.

PRESCHA, A.; ZABŁOCKA, K.; NADUK, J.; GRAJETA, H. Natural mineral and spring waters and fruit juices as food sources of silicon. Rocz Panstw Zakl Hig., v. 62, n. 3, p. 289-293, 2011.

PRICE, C. T.; LANGFORD, J. R.; LIPORACE,
F. A. Essential Nutrients for Bone Health and a Review of their Availability in the Average North American Diet. The Open Orthopaedics Journal, v. 6, p. 143-149, 2012.

RONDEAU, V.; JACQMIN-GADDA, H.; COMMENGES, D.; HELMER, C.; DARTIGUES, J-F. Aluminum and silica in drinking water and the risk of Alzheimer's disease or cognitive decline: findings from 15-year follow-up of the PAQUID cohort. American Journal of Epidemiology, v. 169, n. 4, p. 489-496, 2009.

SCHEER, J. F. Silica: Health \& beauty from nature. Better Nutrition, v. 59, n. 12, p. 1-38, 1997.

SHVARTSEV, S. L. Geochemistry of Fresh Groundwater in the Main Landscape Zones of the Earth. Geochemistry International, v. 46, n. 13, p. 1285-1398, 2008a.

SHVARTSEV, S. L. Interaction in the water-rock system as a new basis for the development of hydrogeology. Russian Journal of Pacific Geology, v. 2, n. 6, p. 465-475, 2008b.

SJOBERG, S. Silica in aqueous environments. Journal of Non-Crystalline Solids, v. 196, p. 51-57, 1996.

SMIRNOVA, I. N.; ZARIPOVA, T. N.; KUZ'MENKO, D. I.; ANTIPOVA, I. I. Anti-inflammatory effect of mineral water inhalation: validity of identification of biochemical markers in nasal secretion. Vopr Kurortol Fizioter Lech Fiz Kult, v. 4, p. 20-23, 2003.

SZIKSZAY, M. Geoquímica das Águas Subterrâneas. Boletim IG-USP Série Didática, v. 17, n. 20, p. 1-165, 1993.

TARDY, Y. Characterization of the principal weathering types by the geochemistry of waters from some European and African crystalline massifs. Chemical Geology, v. 7, p. 253-271, 1971.

TÖLGYESSY, J. The chemistry of water. In: TÖLGYESSY, J. ed. Chemistry and Biology of Water, Air and Soil: Environmental Aspects. Amsterdam: Elsevier, v. 3, p. 14325, 1993. 